DOI: 10.17805/trudy.2016.3.6

\title{
ЖУРНАЛИСТИКА ПУТЕШЕСТВИЙ: РЕАЛЬНОСТЬ И ТЕНДЕНЦИИ
}

\author{
А. А. Бобров \\ (Московский гуманитарный университет)
}

Аннотация: Трэвел-журналистика в современной теории массовых коммуникаций - это особое направление журналистики, которое предоставляет потребителю информацию о дальних путешествиях и родной стране.

Ключевые слова: трэвэл-журналистика; журналистика путешествий; туризм

\section{TRAVEL JOURNALISM: REALITY AND TRENDS}

\author{
A. A. Bobrov \\ (Moscow University for the Humanities)
}

Abstract: Travel journalism is a special sub-field in the contemporary theory of mass communication, the one that provides consumers with information about long-distance travels and their native country.

Keywords: travel journalism; travel writing; tourism

Трэвел-журналистика (или журналистика путешествий) - старинная, расширяющаяся, многогранная и все более востребованная сфера журналистики. Классические образцы ее дали, не помышляя об этом, итальянский купец Марко Поло в «Книге о разнообразии мира» и русский купец Афанасий Никитин в книге «Хождение за три моря», соединив прагматическое и лирическое, познавательное и увлекательное. В давних годах и дорогах, в XIV-XV вв. уже заложены все признаки и принципы этой разновидности словесного творчества.

Несмотря на русскую охоту к перемене мест и российские пространства, которые постоянно зовут в дорогу, на глубочайшие традиции жанра путевого очерка в России, на бурное развитие школьного туризма и краеведения в советские годы, бум культурного туризма после так называемой «оттепели» (вспомнить хотя бы «Золотое кольцо», которое гремело на весь мир, или Волговерховье, когда на Селигере за сезон бывало до 500 тысяч 
организованных и самодеятельных туристов), сама трэвел-журналистика не получила такого развития, как в условиях рыночного Запада, не выделилась в определенный сегмент профессиональной журналистики, продолжая словно балансировать между путевой прозой и просветительской журналистикой на уровне журнала «Турист» и ухудшенных телевариантов «Клуба кинопутешественников». Поэтому кафедры туризма в вузах охотно готовят сегодня менеджеров от туризма, организаторов и работников сервиса, а направление «журналистика путешествий» - не развивается, хотя в Сходне, например, работает целая Международная академия туризма. Но учебных пособий, методических разработок по этому курсу - крайне мало. Автор пытается своими книгами, публикациями, этой статьей внести посильный вклад, соединив теоретическое осмысление с конкретными уроками трэвел-журналистики. Сегодня это крайне важно не только потому, что Россию накрыл очередной экономический кризис, который заставляет людей экономить на всем, в том числе и на путешествиях, не потому, что закрылся целый ряд бюджетных и популярных южных направлений, а против россиян введены санкции, но еще и потому, что журналистика путешествий зовет в дорогу к знаниям, здоровью, красоте, к познанию мира, а главное - Родины!

Эпоха глобализации, власти информационных технологий и чистогана, геополитических противоборств и гибридных войн требует прежде всего защиты и спасения здравого сознания и живой души человека. Если говорить о воспитании молодого поколения, то, как справедливо подчеркивает в своей книге ректор МосГУ И. М. Ильинский «Возникает новый идеал (парадигма) науки и образования, в центре которых - человек в его полномасштабном измерении (тело, ум, эмоции, душа), а также окружающая его среда, как естественно-природная, так и созданная самим человеком - вещная и социальная» (Ильинский, 2005: 14). Эту среду надо постигать, учиться достойно жить в новой реальности, не теряя гуманитарной сущности любого познания. Действительно образованный человек, настоящий журналист - это человек гуманный. Более того, он в идеале - гражданин и патриот своей страны. «Теперь о гражданине: он должен понимать больше, чем специалист: “Что за страна, в которой я живу?”, “Что за события происходят в ней и в мире?”, “Кто правит?”, “Почему все происходит именно так?” Надо знать ответы на эти вопросы и любить свою страну» (Нужно учиться ..., 2003: Электр. ресурс). Путешествие, открытие новых мест и достопримечательностей, общение с интересными людьми помогает отвечать на эти главные вопросы, приобщаться к жизни своей страны, постигать ее, сравнивая с другими странами и перенимая лучшее. Ибо любить можно лишь то, что знаешь, понимаешь разумом и чувствуешь сердцем. Наверное, трэвел-журналистика, даже в 
иноязычном, общепринятом произношении и призвана выполнять эту главную задачу, а уж потом в условиях глобализации и рыночных отношений - удовлетворять потребность в информации, рекламировать и развлекать хоть чтением в пути, хоть интересным рассказом о неведомом. Тут трэвел-журналистика становится еще и досуговой, способствует удовлетворению любопытства и релаксации.

Итак, трэвел-журналистика (от англ. travel journalism) в современной теории массовых коммуникаций - это особое направление журналистики, которое предоставляет массовому потребителю информацию о путешествиях, затрагивает темы истории, географии, культуры, искусства, туризма, этики, философии и другие. Сегодня именно это направление журналистики влияет на национальную самоидентификацию людей, преобразуют информацию из одного культурного контекста в другой, формирует у аудитории определенный образ различных культур и ментальностей, зачастую детерминированный PR-агенствами и редакторами печатных СМИ, телепрограмм и веб-сайтов. «Незаслуженное пренебрежение трэвел-журналистикой парадоксально, потому что происходит во время смещения фокуса масс-медиа с хард-ньюс (англ. hard-news) на софт-ньюс (англ. soft-news), т. е. с серьезной информации на развлекательную и досуговую» (Merriman, 2003: 7). Продолжая этот терминологический ряд, добавим за иностранными исследователями, что популяризации трэвел-журналитики способствуют процессы конвергенции СМИ и экспансии инфотейнмента на телевидении, в интернете - смеси информации и развлечения - как важнейшего тренда развития современных СМИ. При этом, несмотря на писательские пристрастия, автор осознает, что трэвел-журналист занимается прежде всего информационной журналистикой, а не литературой, причем вне зависимости от характера СМИ. Проблема состоит в том, что путевые очерки можно создавать в гораздо более ограниченных условиях: жанр позволяет авторам делать эмоциональные заметки без учета требования СМИ, включать вымышленные элементы и использовать художественные приемы. Возможно даже создание материала без самого путешествия - автор создает придуманные истории для развлечения читателя, используя чужие фотографии, подкрепляя материал фактами из путеводителей. Такие материалы, например, часто встречаются в женских глянцевых журналах: занимательный рассказ, гламурные фото курортов, захватывающие подробности, известные рецепты национальных кухонь, следы пребывания знаменитостей. Это все можно сегодня найти в интернете.

Трэвел-журналистика как коммерческая сфера не всегда следует традиционным журналистским идеалам и редко, к сожалению, руководствуется понятием общественного интереса. Из-за этого содержательный 
баланс в трэвел-журналистике порой колеблется между двумя радикальными полюсами - рекламой и шоу. В действительности, в общей массе - от журнала авиа-экспресса до солидного переводного «Гео» трэвелжурналистика рассказывает об аспектах туризма в информационных и развлекательных целях, что редко включает в себя аналитические аспекты повествования, свойственные серьезной журналистике. К тому же забывается сверхзадача: позвать человека в дорогу не с целью выманить деньги и заполучить клиента, а с целью его культурного обогащения, оздоровления души и тела.

Рольф Поттс - автор книги «Vagabonding» - «Бродяжничество», популярный автор журналов и радиопрограмм для путешественников выработал 5 ключевых способов, которым можно научиться в пути, но применять их можно для того, чтобы сделать свою жизнь богаче и ярче уже дома (Potts, 2002).

Ознакомимся с этими броскими советами, добавив краткие комментарии, возвращающие на грешную землю.

1) Время = Ценность.

Самый главный урок, который можно извлечь из путешествий, заключается в том, что время - единственная ценность, которая есть у вас в жизни. И чем больше вы путешествуете, тем больше понимаете, что самые экстравагантные увлечения не могут сравниться с уровнем удовлетворения, которое дарит получение нового опыта, встреча с новыми людьми, возможность узнать о самом себе что-то новое. «Ценность» - слово, которое часто звучит в повседневной жизни, но путешествие способно научить нас, что ценность не измеряется в количестве денег, а скорее в жизненном опыте, который мы получаем, если куда-то отправляемся (например, на фестиваль в Раджастане, в итальянскую деревушку, или посмотреть рассвет всего в десяти минутах от вашего дома).

А. Б.: Но как туда добраться - до Раджастана без денег, Рольф, чтобы сравнить с закатом у дома? Судя по параллели -у загородного дома, в десяти минутах от виллы, а не рядом с трущобами или со спальным районом?

2) Будьте там, где вы есть.

Путешествие прекрасно тем, что заставляет вас переживать текущий момент. Когда вы празднуете карнавал в Рио или скачете на лошади по монгольской степи, или гуляете по базару в Дамаске, внутри вы трепещете от осознания того, где вы находитесь и что происходит вокруг. В эпоху, когда электронная связь постоянно отвлекает нас в виртуальную реальность, есть особое очарование в том, чтобы ощутить себя в данном месте в данный момент. Разве вы будете проверять банковскую выписку по время путешествия к Манчу-Пикчу в Перу? Будете проверять ленту в Facebook, когда наслаждаетесь белыми ночами в Санкт-Петербурге? Конечно, нет! 
Когда вы путешествуете, вы получаете возможность насладиться лучшими моментами жизни, которая протекает прямо перед вами. И это отношение к жизни не должно ограничиваться путешествием.

А.Б.: Увы, Рольф. Приходится заходить в почтуи во время петербургских бельх ночей, когда, например, студенты направления трэвел-журналистика тянут с курсовыми работами до самого июньского экзамена.

3) Притормозите.

Одно из преимуществ долгосрочного путешествия (в отличие от короткого отпуска) - это возможность не спешить и дать всему идти своим чередом. Вы свободны от узкой туристической программы, вы можете посмотреть вещи (и встретить людей), которые большинство даже не видят в спешке посмотреть все основные достопримечательности в туристическом списке. Масса компаний были созданы для того, чтобы удовлетворять наши потребности в «отдыхе», как дома, так и в дороге, но слишком часто это понимание «отдыха» жестко ограничивается рамками нашей трудовой жизни. Что больше похоже на отдых - три часа в спа в дорогом отеле, или же свободные странствия по Бали в течение месяца.

А. Б.: Рольф, мне в своих дорогах не приходилось сталкиваться с таким выбором: 3 часа в супер-отеле или месяи скитаний. Что ж это за отель такой роскошный и что за нищенская жизнь в течение месяца?

4) Не усложняйте.

В путешествиях вы совершенно естественно начинаете жить простой жизнью, ведь оно заставляет вас обходиться минимумом вещей, которые помещаются в ваш чемодан или рюкзак. Кроме того, в путешествиях вы копите не новые вещи, а впечатления и дружеские связи. И это изменит вашу жизнь так, как не сможет целая куча вещей.

В доме вы тоже можете руководствоваться принципами простоты, что поможет вам жить более просто и одновременно более роскошно. Сколько ваших вещей правда улучшает качество вашей жизни? Какие вещи дарят вам более яркую жизнь, а какие просто загромождают ее? Исследователи выявили, что новый опыт дарит нам такое удовлетворение, которое не могут дать новые вещи. Вы будете более счастливым, если пригласите друга на обед, чем если потратите эту же сумму на рубашку. Так что вкладывайте деньги не в новые вещи, а в новые дела, и это сделает вашу жизнь счастливее. Менее материалистическое состояние ума поможет вам также сэкономить деньги на очередное путешествие.

А. Б.: Рольф, Вы призывается к простоте и отказу от роскоши, от ненужных вещей, потомучто никогда, наверное, не стояли перед типично российским выбором: купить самое необходимое или все-таки отправиться $в$ nутешествие?

5) Не устанавливайте себе ограничений. 
Путешествия раскроют вам глаза, что большая часть всего, что вы слышали о мире, неверно. Ваши семьи или друзья будут говорить вам, что поехать в Колумбию или Ливан смерти подобно. Но когда вы туда отправитесь, то будете просто поражены дружелюбием, красотой и новым взглядом на человеческое общение. Даже на бытовом уровне путешествия помогают вам не устанавливать ограничений на то, что вы можете и чего не можете. В дороге вы сами «играете» с вашим днем: ждете, разглядываете, слушаете, позволяете событиям вокруг вас происходить. Нет лучшей возможности сломать старые привычки, встретиться с тайными страхами, проверить подавленные стороны своей личности.

Однако совсем нет причин, почему вы должны ограничиваться такого рода свободу только временем в путешествии. Тот же самый страх, что не дает людям пуститься в путешествие, мешает вам пробовать новое или встречаться с новыми людьми в своем родном городе. Преодолейте ваши страхи, и вы сможете убежать от рутинной скуки и дома, открытость и уверенность нужны в путешествии, но они так полезны для проверки бизнес идей, оживления отношений с друзьями и семьей. Да они помогут пригласить вам девушку, которая так вкусно пахнет, выпить с вами чашечку кофе. Если вы прекратите ставить самим себе рамки что возможно, а что нет, вы откроете себя целому миру новых возможностей.

А. Б.: Конечно, и домашняя картинка соблазнительна, где и девушка, и кофе «вкусно пахнут», но россиянина держит дома не страх, а нечто другое, чего коснемся далее.

Конечно это только примеры того, как путешествия могут помочь в повседневной жизни.

Но здесь упущено самое главное! В прошлом кризисном 2015 году ВЦИОМ опубликовал результаты опроса, посвященного предпочтениям россиян, которые касаются мест проведения летнего отдыха, сообщил сайт http://luchshiydrug.ru. И хотя почти тридцать процентов наших граждан идеальным считают отпуск, проведенный в дальних странах, на практике основная масса жителей России проводят его дома или на даче (Лето-2015 ..., Электр. ресурс). Отметим, что большая часть наших граждан, как и ранее, предпочитает пляжный отдых, популярность которого непрерывно растет: еще семь лет назад отдыхать таким образом предпочитали около 30\% россиян, а сегодня эта цифра равна $36 \%$.

Увы, менее популярны культурно-познавательные поездки, санаторное лечение, рыбалка и охота, походы и экстремальный туризм. А ведь именно последними направлениями и возможностями так богата Россия! Третье место рейтинга мест, где россияне хотели бы провести летний отпуск, занимает... дом. Как ни странно, 16\% опрошенных, даже при наличии финансовой возможности, предпочитает отдыхать дома в кругу семьи. 
Но, несмотря на все теоретические предпочтения, остается прискорбным факт, что желания наших граждан в последние два года контрастно не соответствуют их финансовым возможностям. Позволить себе туры за границу могут только 5\% соотечественников! Вот и рассуждай о «главной достижении» либерализации - свободе передвижения по миру! При этом есть еще более грустный показатель: половина опрошенных будет отдыхать дома из-за финансовых затруднений, а четверть проведет отпуск на даче или в огороде. И лишь 10\% смогут себе позволить выехать в другой город в России. Лишь каждый десятый отправится по родной стране!

О чем говорят эти цифры, которых никогда не постигнет, не осмыслит американец Рольф? Люди, воспитанные на «Непутевых заметках» Дмитрия Крылова и на «Орле и решке» с золотой безлимитной картой, не могут поехать, с одной стороны, туда, куда хотели бы в фантазиях, а, с другой - не знают, где можно замечательно отдохнуть по средствам, с пользой, пусть и без привлекательной экзотики. Вот почему нам надо развивать внутренний недорогой, но познавательный и оздоровляющий туризм по доступным ценам, а еще - рассказывать о стране ярко и увлекательно, звать в дорогу по родному краю.

Когда-то к таким походам и к экскурсиям приучали со школьной скамьи, а продолжали в техникумах и вузах. Выдающийся педагог Макаренко, работая в колонии им. Ф. Э. Дзержинского в подмосковной Угреше, где останавливался на ночевку с войском Дмитрий Донской, идя на Куликово поле, был убежден, что нет лучше метода развития и образования молодежи, как летние походы. Сколько их теперь проводится - никто не назовет. Но мы ведь почти не видим в электричках, на автобусных остановках организованных групп ребят с рюкзаками и гитарами, а еще 30 лет назад от них звенело туристско-пионерское лето.

Эта сфера эта требует возрождения, пристальной государственной заботы и развития. Не случайно ведь в конце мая 2012 г. туристская отрасль была передана из Минспорттуризма в Министерство культуры. Это было закреплено Указом Президента «О структуре федеральных органов исполнительной власти». Соответственно, в ведение Минкульта перешло Федеральное агентство по туризму (Ростуризм). Было повторено на самом высоком уровне, что главными задачами индустрии туризма, помимо оздоровления, являются повышение культурного уровня человека, более полное удовлетворение духовных потребностей, оказание положительного влияния на его систему ценностей, знаний, общественное поведение.

Ведущую роль среди основных видов туризма занимает культурнопросветительный (культурно-познавательный) туризм. Конечно, нельзя забывать и об экономической стороне: мировой туристический поток уже превысил 1 млрд. человек, а к 2030 г., по прогнозам Всемирной ту- 
ристской организации (гуманитарная ВТО), удвоится. При этом Россия, имея 5-й в мире туристический потенциал, занимает лишь 59-е место по посещаемости туристами.

Передача сферы туризма в Министерство культуры поставили и новые задачи и перед учебными заведениями. Конечно, во многих вузах готовят специалистов в сфере таможенного дела и турбизнеса, выпускают «бакалавров туризма» по специализации: «Технология и организация туроператорской и турагентской деятельности», «Организация гостиничного хозяйства» и т. п. В МосГУ тоже можно получить квалификацию бакалавра по направлению подготовки «Туризм», где студенты будут проектировать программы туров, турпакетов, разрабатывать экскурсионные программы, организовывать комплексное туристическое, коммуникации и продвижение на рынок туристических услуг.

Вот последнее уже ближе к специальности «Журналистика». Но кафедра журналистики на факультете рекламы озабочена главным, как готовить специалистов в этой сфере не только с точки зрения менеджмента, социальных услуг, но прежде всего в области содержательной - культурнопросветительского туризма, краеведения, связей с территориями России, обладающими огромным туристским потенциалом, с братскими славянскими странами, как бы трагически ни складывались отношения с некоторыми из них. Кто расскажет о красотах России, о культурном и целебном потенциале уникальных мест? Прежде всего - журналисты, которые просветят и позовут в дорогу! Потому мы и намереваемся развивать это направление. На нем, кроме общефилологических и журналистских дисциплин должны быть специальные предметы, курсы и тематические блоки:

- Краеведение и познавательная литература

- Информационное обеспечение туристской деятельности

- Паломнический туризм и основы главных религий России

- Санаторно-курортное дело и целебные края России

- Культуроведение и охрана памятников истории

- Экология и спортивно-оздоровительный туризм

- Экономика и менеджмент в сфере туризма

За этим направлением - будущее во всем мире. Не лишне заметить, что по прикидкам Всемирной туристской организации, к 2030 г. число международных туристов достигнет 1,8 миллиарда человек (К 2030 году ..., Электр. ресурс).

Президент России Владимир Путин на региональной встрече с представителями Общенационального народного фронта в Йошкар-Оле в апреле 2016 года особо подчеркнул, что возможности внутреннего туризма в России - безграничны (Белобородова, 2016: Электр. ресурс). Значит, неисчерпаемы и возможности журналистики путешествий. Для 
расширения их использования надо готовить кадры не только организаторов, но и популяризаторов, не только администраторов и поваров, но и литераторов-мастеров.

\section{СПИСОК ЛИТЕРАТУРЫ}

Белобородова, О. (2016) «Без материального культурного наследия трудно представить себе Россию» // Взгляд. 25 апреля. URL: http://vz.ru/ politics/2016/4/25/807344.print.html (дата обращения: 12.05.2016).

Ильинский, И. М. (2005) Формула успеха (самоинтервью в форме диалога Реалиста со Скептиком). М. : Изд-во Московского гуманитарного университета. 52 с.

К 2030 году число международных туристов достигнет 1,8 миллиарда человек (2011) // РЦБ.РФ. 14 октября. URL: http://www.rcb.ru/news/97547/ (дата обращения: 12.05.2016).

Лето-2015: планы на отдых, бюджет, ожидания россиян [Электронный pесурс]//ВЦИОМ. 3 июня.URL: http://infographics.wciom.ru/theme-archive/ society/religion-lifestyle/travel/article/leto-2015-plany-i-predpochtenijarossijan (дата обращения: 12.05.2016).

Нужно учиться всю жизнь (2013) [Электронный ресурс] // Аргументы и факты. 11 февраля. URL: http://www.aif.ru/archive/1697959 (дата обращения: 14.05.2016).

Merriman, E. (2003) Soft News, the Rise of Critical Journalism, and How to Preserve Democracy. EDGE. Spring Quarter.

Potts, R. (2002) Vagabonding. Gardners Books.

Бобров Александр Александрович - кандидат филологических наук, профессор кафедры журналистики Московского гуманитарного университета. Адрес: 111395, Россия, г. Москва, ул. Юности, д. 5. Тел.: +7 (499) 374-60-91. Эл. адрес: bobr304@yandex.ru

Bobrov Aleksandr Aleksandrovich, Candidate of Philology, Professor, Department of Journalism, Moscow University for Humanities. Postal address: 5 Yunosti St., 111395 Moscow, Russian Federation. Tel.: +7 (499) 374-60-91. E-mail: bobr304@yandex.ru 